\section{(6) OPEN ACCESS}

\title{
Host cell mTORC1 is required for HCV RNA replication
}

\author{
Stefanie Stöhr, ${ }^{1,2}$ Rui Costa, ${ }^{1}$ Lisa Sandmann, ${ }^{1,2}$ Sandra Westhaus, ${ }^{1,2,3}$ \\ Stephanie Pfaender, ${ }^{4}$ Anggakusuma, ${ }^{4}$ Eva Dazert, ${ }^{5}$ Philip Meuleman, ${ }^{6}$ \\ Florian W R Vondran, 2,7 Michael P Manns, ${ }^{1,2}$ Eike Steinmann, ${ }^{4}$ \\ Thomas von Hahn, ${ }^{1,2,3}$ Sandra Ciesek ${ }^{1,2,8}$
}

\begin{abstract}
- Additional material is published online only. To view please visit the journal online (http://dx.doi.org/10.1136/ gutjn-2014-308971).
\end{abstract}

For numbered affiliations see end of article.

\section{Correspondence to} Dr Sandra Ciesek, Medizinische Hochschule Hannover, Klinik für Gastroenterologie, Hepatologie und Endokrinologie, Carl-NeubergStr. 1, Hannover 30625 Germany; Ciesek.sandra@mhhannover.de

SS and RC contributed equally.

Received 8 December 2014 Accepted 10 July 2015 Published Online First 14 August 2015

\section{CrossMark}

To cite: Stöhr S, Costa $\mathrm{R}$, Sandmann L, et al. Gut 2016;65:2017-2028.

\section{ABSTRACT}

Objective Chronically HCV-infected orthotopic liver transplantation (OLT) recipients appear to have improved outcomes when their immunosuppressive regimen includes a mammalian target of rapamycin (mTOR) inhibitor. The mechanism underlying this observation is unknown.

Design We used virological assays to investigate mTOR signalling on the HCV replication cycle. Furthermore, we analysed HCV RNA levels of 42 HCV-positive transplanted patients treated with an mTOR inhibitor as part of their immunosuppressive regimen.

Results The mTOR inhibitor rapamycin was found to be a potent inhibitor for HCV RNA replication in Huh-7.5 cells as well as primary human hepatocytes. Half-maximal inhibition was observed at $0.01 \mu \mathrm{g} / \mathrm{mL}$, a concentration that is in the range of serum levels seen in transplant recipients and does not affect cell proliferation. Early replication cycle steps such as cell entry and RNA translation were not affected. Knockdown of raptor, an essential component of mTORC1, but not rictor, an essential component of mTORC2, inhibited viral RNA replication. In addition, overexpression of raptor led to higher viral RNA replication, demonstrating that $\mathrm{MTORC1}$, but not $\mathrm{MTORC2}$, is required for HCV RNA replication. In $42 \mathrm{HCV}$-infected liver-transplanted or kidney-transplanted patients who were switched to an mTOR inhibitor, we could verify that mTOR inhibition decreased HCV RNA levels in vivo.

Conclusions Our data identify mTORC1 as a novel $\mathrm{HCV}$ replication factor. These findings suggest an underlying mechanism for the observed benefits of mTOR inhibition in HCV-positive OLT recipients and potentiate further investigation of mTOR-containing regimens in HCV-positive recipients of solid organ transplants.

\section{INTRODUCTION}

Infection with the HCV commonly causes chronic liver disease and thus remains a major indication for orthotopic liver transplantation (OLT) worldwide. ${ }^{1}$ Approximately 170 million individuals are chronically infected. Pegylated interferon alpha in combination with ribavirin was the standard of treatment, until 2011, when the first direct acting antiviral (DAA) drugs were approved. ${ }^{2}$ DAA are currently employed in interferon-containing and interferon-free combinations and have led to higher

\section{Significance of this study}

What is already known on this subject?

- Immunosuppression based on mammalian target of rapamycin (mTOR) inhibitors results in slower disease progression and reduced rates of advanced fibrosis in HCV-positive recipients after liver transplantation.

- Treatment with the mTOR inhibitor rapamycin significantly suppressed viral replication in HCV-positive renal transplanted patients.

- HCV activates mTOR signalling to inhibit apoptosis and affects mTOR signalling to influence glucose metabolism.

What are the new findings?

- mTOR inhibitors are able to block HCV RNA replication independent from cytotoxic or antiproliferative effects.

- Knockdown of raptor, an essential component of mTOR complex 1, inhibited viral RNA replication.

- mTOR complex 1 is a previously unknown essential host factor for HCV RNA replication.

- Treatment with mTOR inhibitors reduces HCV RNA levels in patients after liver and kidney transplantation.

How might it impact on clinical practice in the foreseeable future?

- Our study provides a possible underlying mechanism for the clinical observation that mTOR inhibition is beneficial in HCV-positive orthotopic liver transplantation recipients. Moreover, this might be a rationale for further evaluating mTOR inhibitor containing regimens in this difficult-to-treat population.

response rates with fewer side effects. ${ }^{3}{ }^{4}$ However, prevention of HCV reinfection of the graft after OLT is still an unresolved problem in clinical practice and antiviral treatment of HCV after OLT remains challenging. ${ }^{156}$ Interactions between antiviral and immunosuppressive drugs and their severe side effects in combination with other comorbidities lead to inferior outcomes of HCV-positive OLT recipients compared with those who are transplanted for other indications. ${ }^{7}$ Within 5 years after 
transplantation, up to $30 \%$ of patients redevelop cirrhosis and are therefore at risk of decompensation and need for retransplantation. ${ }^{8}$ Consequently, survival rates of HCV-infected liver transplanted patients are below those of uninfected ones. ${ }^{10}$ The accelerated progression of chronic hepatitis C in OLT recipients is thought to be at least in part due to immunosuppression allowing enhanced viral replication. In addition, we have been able to show that glucocorticoids that are routinely part of immunosuppressive regimens have direct pro-viral effects. ${ }^{11}$ Optimising immunosuppressant regimens might be a conceivable key factor in improving outcome in HCV-positive OLT recipients, yet clinical data on different agents remain inconclusive. ${ }^{1}$ Thus at present, a triple combination of a calcineurin inhibitor (tacrolimus or cyclosporine A (CsA)) in combination with mycophenolate mofetil and steroids remains the standard approach to prevent long-term rejection. ${ }^{12}$ Different regimens with more pronounced inherent antiviral activity would be an attractive prospect.

Inhibitors of the serine/threonine kinase mammalian target of rapamycin (mTOR) are an increasingly employed class of immunosuppressive drugs, but their exact impact on the HCV replication cycle is unknown. mTOR is a key component of two structurally and functionally distinct protein complexes that regulate cell signalling pathways by phosphorylating several downstream targets. ${ }^{13}{ }^{14}$ These regulate host cell energy as well as cell growth and metabolism in response to nutrients and growth factors. ${ }^{15}$ The mTOR protein is present in two distinct complexes, the mTOR complex 1 (mTORC1) and mTOR complex 2 (mTORC2), that are activated by different classes of stimulators and differ in their upstream and downstream effectors. ${ }^{14}$ mTORC1 contains regulatory associated protein of mTOR (raptor) and controls growth-related processes, such as protein synthesis, cellular autophagy, lipid synthesis and progression through the cell cycle. ${ }^{16}{ }^{17}$ Rapamycin and everolimus bind to the mTOR-FRB (FKBP12/rapamycin-binding domain), which exclusively leads to inhibition of mTORC1. Thus, proliferation, especially of tumour cells and T-cells, is inhibited, resulting in an immunosuppressive effect. ${ }^{18}$ mTORC2 activates the protooncogene Akt (S473) and is responsible for cell survival, regulation of metabolism and cytoskeletal dynamics. ${ }^{19}$ In contrast to mTORC1, mTORC2 comprises the rictor (rapamycin-insensitive companion of mTOR) protein and is insensitive to rapamycin and everolimus inhibition, ${ }^{19}$ at least in short-term treatments. Long-term administered rapamycin also affects mTORC $2 .{ }^{20}$

Inhibitors of the mTOR like everolimus and rapamycin are important drugs in tumour therapy and immunosuppression after solid organ transplantation. ${ }^{21} 22$ A retrospective study evaluating the benefit of mTOR inhibitor treatment in $>500$ HCV-positive liver recipients has shown that mTOR inhibitors slow down disease progression and reduce rates of advanced fibrosis in $\mathrm{HCV}$-positive recipients. ${ }^{23}$ In addition, Asthana et $\mathrm{al}^{24}$ observed in a retrospective analysis of 141 patients that de novo rapamycin-based immunosuppression leads to slower progression of fibrosis. In an interventional open-label prospective study, renal transplanted patients with HIV and HCV benefited from rapamycin monotherapy in comparison to treatment with CsA. ${ }^{25}$ Moreover, rapamycin treatment significantly suppressed viral replication in $\mathrm{HCV}$-positive renal transplanted patients compared with patients receiving CsA. ${ }^{25}$ However, little is known about the relation between mTOR-mediated signalling and HCV RNA replication from a molecular point of view. It is known that $\mathrm{HCV}$ activates mTOR signalling to inhibit apoptosis, which may promote chronic infection. ${ }^{26}$
In addition, $\mathrm{HCV}$ affects mTOR signalling to influence glucose metabolism by inhibition of TSC-1/TSC- 2 and consequently activation of mTORC1 and S6K1. ${ }^{27} 28$ However, whether mTOR-mediated signalling has direct effects on the HCV replication cycle is unknown. This study was undertaken to clarify this point.

Based on multiple lines of evidence, we show that mTORC1 is a previously unknown essential host factor for $\mathrm{HCV}$ RNA replication and new particle production since these key processes of the HCV replication cycle depend on mTORC1-mediated but not mTORC2-mediated signalling. Thus, we provide a possible underlying mechanism for the clinical observation that mTOR inhibition is beneficial in HCV-positive OLT recipients and a rationale for further evaluating mTOR inhibitor containing regimens in this difficult-to-treat population.

\section{MATERIALS AND METHODS Compounds}

Rapamycin (sirolimus, molar mass $914.172 \mathrm{~g} / \mathrm{mol}$ ), everolimus (molar mass $958.224 \mathrm{~g} / \mathrm{mol}$ ), LY-294002 hydrochloride, PP242 hydrate and mitomycin were purchased from Sigma-Aldrich, Seelze, Germany.

\section{HCV replication and infection assay}

Huh-7.5 cells were electroporated with $5 \mu \mathrm{g}$ RNA of the reporter virus Luc-Jc1 (genotype $2 \mathrm{a}$ ) as described. ${ }^{29}$ After $4 \mathrm{~h}$, different concentrations of rapamycin or everolimus were added to the cell culture medium. HCV RNA replication was quantified by measuring luciferase activity. After $48 \mathrm{~h}$, supernatants were collected, filtered through $0.45 \mu \mathrm{m}$ pore size filters and used to infect naive Huh-7.5 target cells. In general, $500 \mu \mathrm{L}$ containing virus supernatant with a viral titre of $1 \times 10^{4}$ in $\mathrm{TCID}_{50}$ (multiplicity of infection (MOI) $0.05-0.1$ ) was used to inoculate target cells. HCV titres were determined as published recently. ${ }^{30}$ The $50 \%$ tissue culture infectious dose $\left(\mathrm{TCID}_{50}\right)$ was calculated based on the methods described by Spearman and Kaerber.

\section{Patient characteristics}

All kidney-transplanted or liver-transplanted patients with chronic HCV (genotype 1) at Hannover Medical School have been reviewed for a switch of their immunosuppressive regimen to an mTOR inhibitor. HCV RNA levels were compared up to 4 weeks before the introduction of the mTOR inhibitor and 4-12 weeks after the change of the immunosuppressive regimen. Trough levels of the mTOR inhibitor were adjusted to $4-8 \mathrm{ng} / \mathrm{mL}$.

\section{Software and statistical analyses}

Data were analysed using Excel (Microsoft, Redmond, Washington, USA) or GraphPad Prism 5 (GraphPad Software, La Jolla, California, USA). In vitro experiments were repeated on separate occasions. Each repetition was performed in multiple replicates. The mean $\pm S D$ of the replicates from one representative experiment is shown with the number of replicates indicated. Unpaired two-sided Student's $t$ test or one-way analysis of variance (ANOVA) with Bonferroni post test were performed accordingly to determine statistical significance. One-way ANOVA was performed to determine statistical significance. Values are represented by $* \mathrm{p}<0.05, * \mathrm{p}<0.01$ and $* *$ p $<0.001$ 


\section{RESULTS}

Rapamycin inhibits HCV RNA replication, but has no effect on HCV entry

To ensure that mTOR signalling is active during HCV cell culture-derived particles $(\mathrm{HCVcc})$ infection, Huh-7.5 cells were transfected with $\mathrm{HCVcc}$ and treated with rapamycin for $48 \mathrm{~h}$. Phosphorylation of mTOR and the downstream protein p70S6K was measured using a chemiluminescent assay, which detects cellular proteins only when phosphorylated at the specified residues. In HCVcc-infected Huh-7.5 cells, we observed an
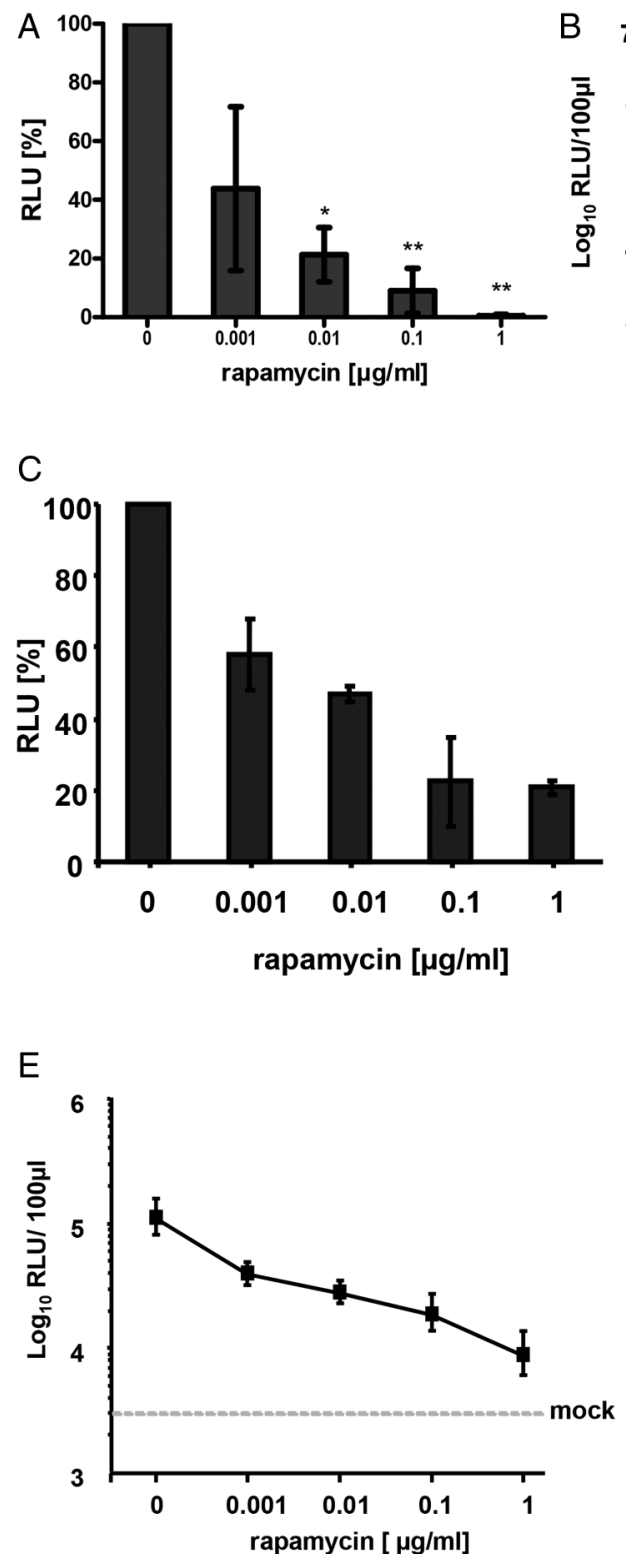
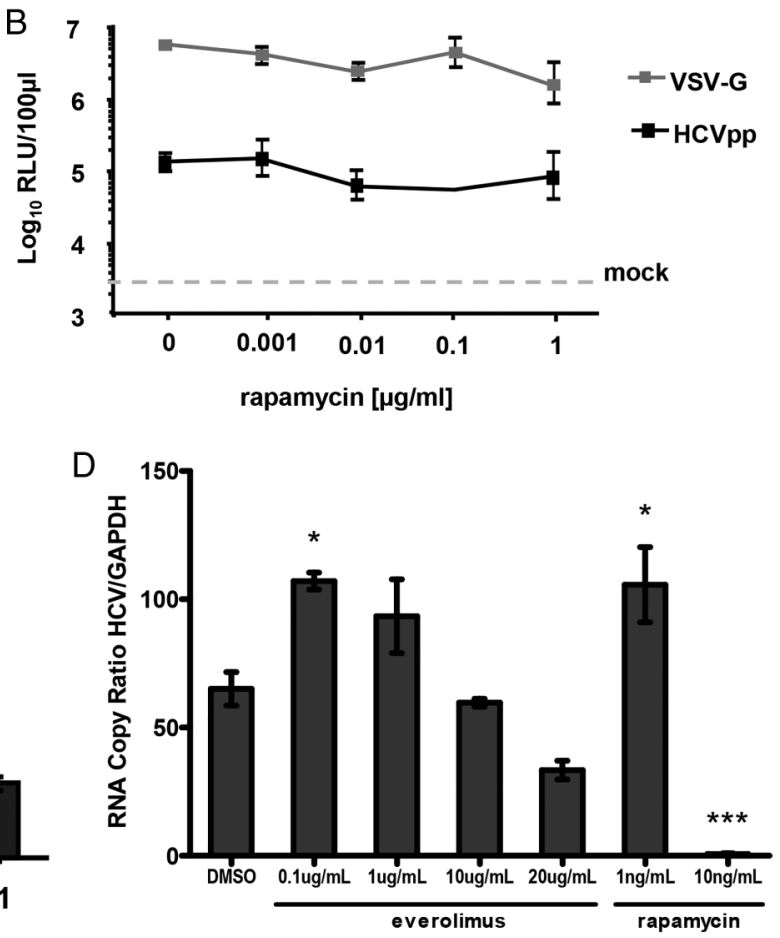

$\mathrm{F}$
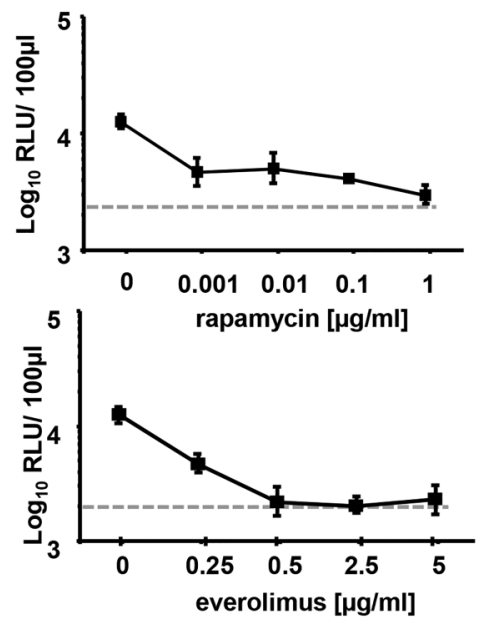

Figure 1 Rapamycin inhibits HCV RNA replication and production of new particles, but had no effect on HCV entry. (A) Huh-7.5 cells were inoculated with Luc-Jc1 reporter viruses in the presence of rapamycin. Infected cells were lysed 3 days later and luciferase activity was determined. The mean of three independent repetitions performed in triplicates is shown. Results were normalised to untreated control. ${ }^{*} p<0.05,{ }^{* *} p<0.01,{ }^{* * *} p<0.001$ by one-way analysis of variance (ANOVA). (B) Huh-7.5 cells were transduced with HCV pseudoparticles (HCVpp) of genotype 1b (Con1) in the presence of rapamycin. The inoculum was removed $4 \mathrm{~h}$ later. Infected cells were lysed 3 days later and luciferase activity was determined. A representative experiment of three independent repetitions performed in triplicates is shown. (C) Huh-7.5 cells were electroporated with the reporter virus Luc-Jc1 and $4 \mathrm{~h}$ later rapamycin was added. Replication efficiency after $48 \mathrm{~h}$ was assessed using a luciferase assay. Mean of three independent experiments performed in duplicates is shown. Results are expressed as per cent of untreated control. ${ }^{*} p<0.05,{ }^{* *} p<0.01,{ }^{* *} p<0.001$ by one-way ANOVA. (D) Huh-7.5 cells were infected with Jc1 wildtype virus and $4 \mathrm{~h}$ later rapamycin or everolimus was added. Inhibition of HCV RNA replication was measured by quantitative real-time PCR. Results were normalised to glyceraldehyde 3-phosphate dehydrogenase (GAPDH). Mean of four independent experiments performed in duplicates is shown. ${ }^{*} p<0.05,{ }^{* *} p<0.01,{ }^{* * *} p<0.001$ by one-way ANOVA. (E) $48 \mathrm{~h}$ culture fluid of the cells from (C) was used to inoculate naïve Huh-7.5 cells. Infected cells were fixed 3 days later and luciferase activity was determined. A representative experiment performed in triplicates of three independent repetitions with SDs of the means is shown. (F) Differentiated Huh-7.5 cells were produced by treatment with dimethyl sulfoxide (DMSO). Then the cells were inoculated with Luc-Jc1 viruses in the presence of rapamycin or everolimus. $48 \mathrm{~h}$ later luciferase signal was measured. Mean values and SDs of four independent experiments are shown. RLU, relative light units; VSV, vesicular stomatitis virus. 
increase in mTOR and $\mathrm{p} 70 \mathrm{~S} 6 \mathrm{~K}$ phosphorylation relative to naive Huh-7.5 cells (see online supplementary figure S1A). These experiments were also confirmed in primary human hepatocytes $(\mathrm{PHH})$ as a more relevant in vitro system. Importantly, treatment with rapamycin in HCV-infected cells reduces phosphorylation of mTOR and p70S6K, confirming inhibition of mTOR catalytic activity following rapamycin treatment in Huh-7.5 cells and PHH. In addition, we investigated whether HCV infection changes endogenous mTOR levels in Huh-7.5 cells and $\mathrm{PHH}$, but could not observe any significant differences (see online supplementary figure S1B).

Next we evaluated the effects of the commonly used mTOR inhibitor rapamycin on HCV replication and infectivity using firefly luciferase reporter viruses. First, we used full-length HCV cc to infect naive Huh-7.5 cells and added increasing concentrations of rapamycin. As shown in figure 1A, the mTOR antagonist inhibits $\mathrm{HCVcc}$ infection in a dose-dependent manner (figure 1A, IC50 $0.10 \mathrm{nM}$ ). To further investigate which step of the viral replication cycle is affected, we used HCV pseudoparticles (HCVpp) to assess specifically the influence on HCV entry. Viral entry of HCVpps derived from genotype $1 \mathrm{a}$ (figure 1B) and genotype 2a (data not shown) was not affected by rapamycin, indicating that $\mathrm{HCV}$ cell entry is unaffected by mTOR inhibition.
To further elucidate the effects on HCV RNA replication, Huh-7.5 cells were electroporated with the reporter virus genome and $4 \mathrm{~h}$ later increasing doses of rapamycin were added. Replication efficiency was assessed $48 \mathrm{~h}$ after transfection using luciferase assay. A dose-dependent inhibition of $\mathrm{HCV}$ RNA replication was detectable (figure $1 \mathrm{C}$ ). In addition, we also used JFH1 subgenomic replicons to study the effect on HCV replication. Inhibition of a JFH1 subgenomic replicon by rapamycin was lower in comparison to a full-length virus or an NS2-5B replicon as well as a Con1 replicon (genotype 1), suggesting that rapamycin sensitivity may be linked to replication fitness of HCV RNAs (see online supplementary figure S2A).

To mimic a chronic HCV infection, we treated Huh-7.5 cells that stably express a neomycin-resistant JFH1 replicon (Luc Ubi Neo JFH1 NS3-3') with rapamycin and measured HCV replication after $48 \mathrm{~h}$. As shown in online supplementary figure S2B, mTOR inhibition also has an antiviral effect on an already established ongoing replication.

To rule out that the antiviral effect is due to an inhibition of luciferase activity and not a direct effect on HCV RNA replication, we used a non-genetically modified virus (Jc1 wildtype) and measured inhibition of HCV RNA by quantitative real time (RT)-PCR. At concentrations, which were in clinical use, we could detect an inhibition of HCV RNA replication. However,
A

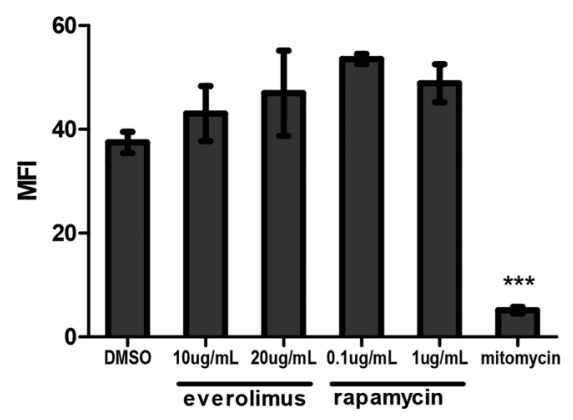

C

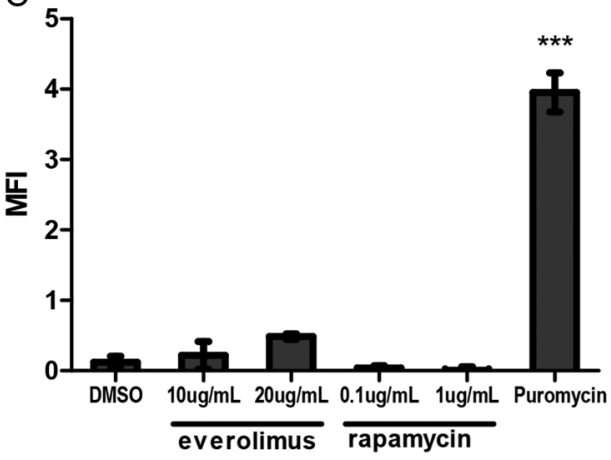

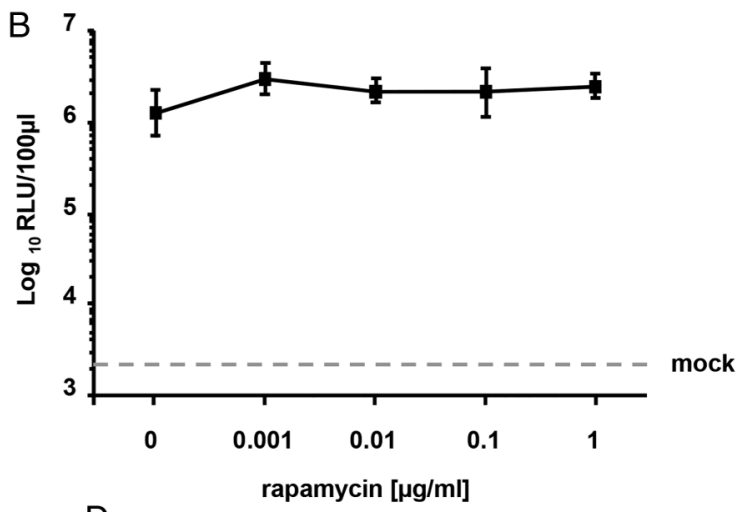

D

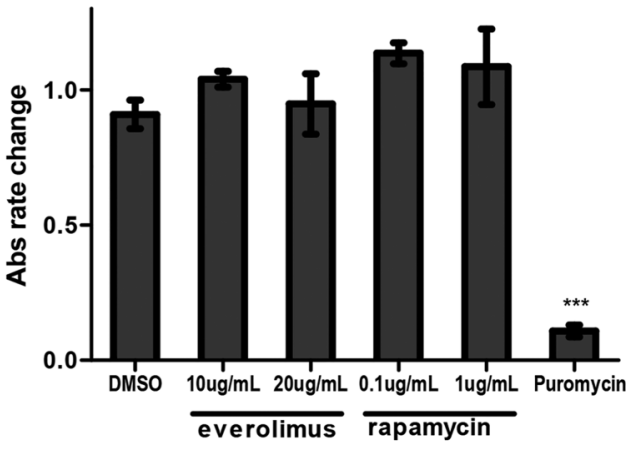

Figure 2 Inhibition of HCV by rapamycin is not due to antiproliferative or cytotoxic effects. (A) Huh-7.5 cells were treated with increasing concentrations of rapamycin in the presence of EdU, a nucleoside analogue to thymidine. $48 \mathrm{~h}$ later, EdU incorporation was measured by fluorescene-activated cell sorting (FACS). Mitomycin served as positive control. Mean fluorescence intensity (MFI) was determined using the geometric mean of the gated population. Mean values and SEM of three independent experiments are shown. ${ }^{*} p<0.05,{ }^{* *} p<0.01,{ }^{* * *} p<0.001$ by one-way analysis of variance (ANOVA). (B) Huh-7.5 stably expressing firefly luciferase from a cytomegalovirus promoter (Huh-7.5/Fluc) were incubated with rapamycin for $72 \mathrm{~h}$. Then cells were fixed and luciferase signal was determined. Mean values and SDs of three independent experiments are shown. (C) Huh-7.5 were incubated for $48 \mathrm{~h}$ with increasing concentrations of the drugs. Cells were then stained with propidium iodide. Dye incorporation was measured by FACS. MFI was determined using the geometric mean of the gated population. Mean values and SEM of three independent experiments are shown. Puromycin was used as a positive control. ${ }^{*} p<0.05,{ }^{* *} p<0.01,{ }^{* * *} p<0.001$ by one-way ANOVA. (D) Huh-7.5 were incubated for $48 \mathrm{~h}$ with increasing concentrations of the drugs. Cells were then incubated with $1.2 \mathrm{mM}$ MTT. Absorbance at $540 \mathrm{~nm}$ was then read on a plate reader. Mean values and SEM of three independent experiments with five replicates per drug concentration are shown. Puromycin was used as a positive control. ${ }^{*} p<0.05,{ }^{* *} p<0.01,{ }^{* * *} p<0.001$ by one-way ANOVA. 
for sub-therapeutical concentrations of rapamycin and everolimus there is a slight increase in viral RNA, as shown in figure $1 \mathrm{D}$.

In parallel, supernatant from electroporated and rapamycintreated cells from figure 1C was used to inoculate naive cells in order to detect a possible influence of the drug on virus production (figure 1E). As expected and in line with reduced HCV RNA replication, we could observe that production of new viral particles was affected. All experiments (figure 1A-E) were performed with both US Food and Drug Administration-approved mTOR inhibitors (rapamycin and everolimus) leading to similar results. To rule out that the inhibitory effect is limited to a genotype 2 isolate, we also tested the antiviral effect of rapamycin on a genotype 3 chimeric full-length virus in direct comparison with a genotype $2 \mathrm{a}$ isolate. As shown in online supplementary figure S3, rapamycin also inhibited replication of a HCV genotype 3 chimeric isolate.

Finally, we generated differentiated Huh-7.5 cells as previously reported by Sainz et al. ${ }^{8}$ Upon differentiation Huh-7.5 cells stop dividing, enter G0 state and assume a more 'differentiated' hepatocyte-like state characterised by upregulation of liver-specific genes such as albumin, $\mathrm{HNF} 4 \alpha$ and $\alpha 1$-antitrypsin. Differentiated Huh-7.5 cells were infected and treated with different concentrations of rapamycin. As in undifferentiated Huh-7.5 cells, we could observe that rapamycin inhibits HCV RNA replication in a dose-dependent manner (figure $1 \mathrm{~F}$ ), indicating that the effect on HCV RNA replication is independent from cell proliferation.

These data suggest that the mTOR inhibitors potently inhibit HCV RNA replication but not viral entry. Importantly, the effect of rapamycin on HCV RNA replication was similar in dividing and non-dividing cells.

\section{Inhibition of HCV by rapamycin is not caused by} antiproliferative or cytotoxic effects

To test whether the inhibitory effect of rapamycin on HCV RNA replication is due to direct antiviral activity or indirectly mediated through non-specific cytotoxic and/or antiproliferative effects of the drug, we used different cytotoxicity and proliferation assays. Since rapamycin is known to be a potent inhibitor of cell proliferation, we performed a standard EdU proliferation assay. In this assay, we could not observe any significant growth arrest after treatment with concentrations of rapamycin we used for our in vitro experiments in this study (figure 2A). The proliferation inhibitor mitomycin $\mathrm{C}$ served as a positive control. As an aggregate measure of cell proliferation and viability, we used
A

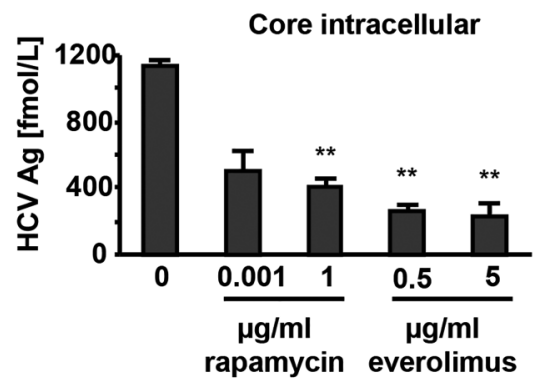

Core extracellular

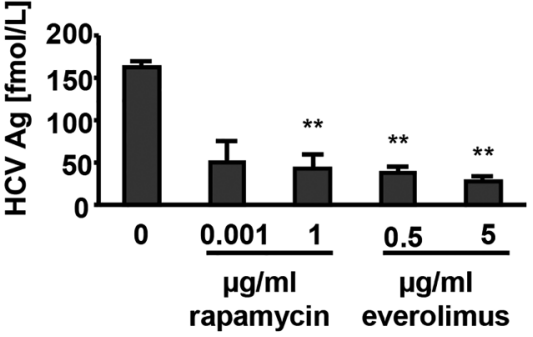

B
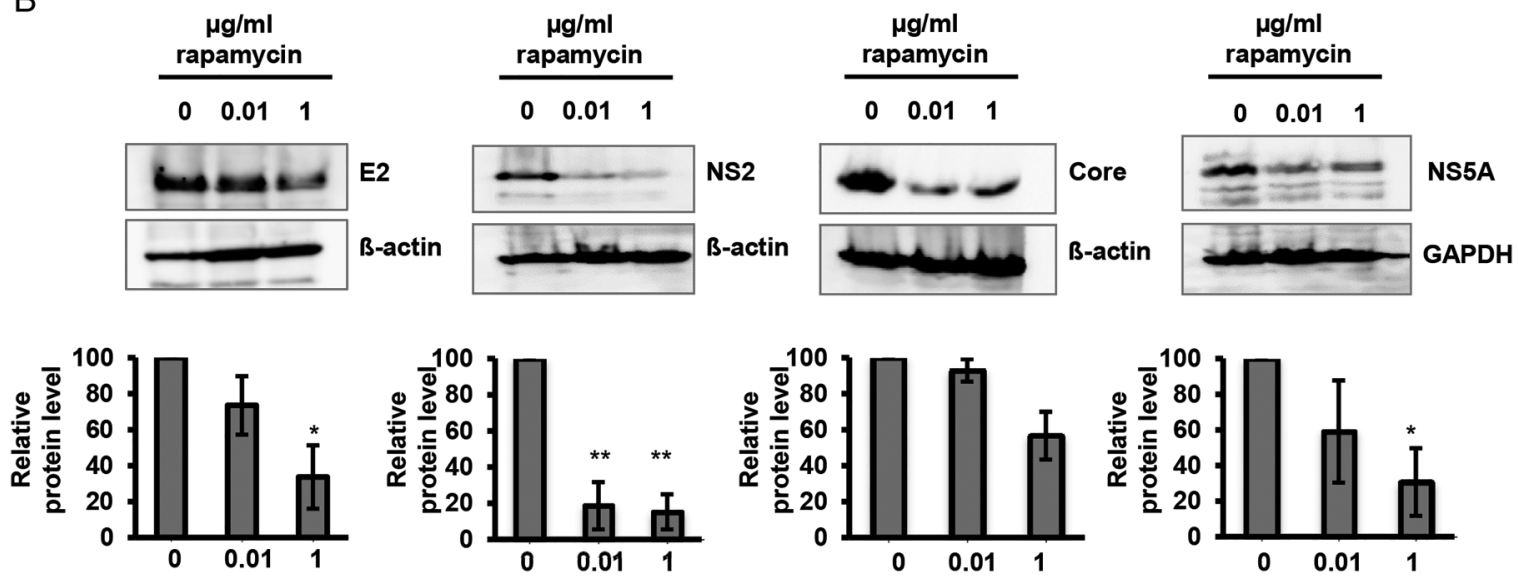

Figure 3 Rapamycin has no influence on new viral particle production and the lipoprotein association of virus particles. (A) Huh-7.5 cells were transfected with Luc-Jc1 and inoculated with mammalian target of rapamycin (mTOR) inhibitors. After $48 \mathrm{~h}$, intracellular and extracellular core levels were measured. Mean values of two independent experiments are shown. ${ }^{*} p<0.05,{ }^{* *} p<0.01,{ }^{* *} p<0.001$ by one-way analysis of variance (ANOVA). (B) Huh-7.5 cells were treated with rapamycin for $48 \mathrm{~h}$ in two different concentrations. Levels of HCV proteins E2, NS2, core and NS5A were determined by western blot. Mean of three independent experiments and a representative western blot are shown. ${ }^{*} p<0.05$, ${ }^{*} p<0.01$, ${ }^{* * *} p<0.001$ by one-way ANOVA. (C) Huh-7.5 cells were pretreated with increasing concentrations of rapamycin for $24 \mathrm{~h}$. Then cells were washed three times with phosphate buffered saline and inoculated with Luc-Jc1 virus. $48 \mathrm{~h}$ after infection luciferase signal was measured. Mean values and SD of three independent experiments are shown. (D) Buoyant density and specific infectivity of Jc1 viruses treated with rapamycin versus untreated. Jc1 was harvested $48 \mathrm{~h}$ after transfection of Huh-7.5 cells \pm rapamycin and were resolved using an iodixanol step gradient. Ten fractions were harvested from the bottom, and HCV core protein, HCV RNA, and infectivity were determined for each fraction. Values are plotted against the density of the respective fraction measured by refractometry. The results are from a representative of two independent experiments. (E) Huh-7.5 cells were transfected with Jc1 wildtype and $48 \mathrm{~h}$ post-transfection supernatants were collected. In parallel, virus-producing cells were washed and lysed by repetitive cycles of freeze and thaw. Extracellular (dark grey bars) and intracellular infectivity (light grey bars) were determined by limiting dilution assay. Mean values of three independent experiments and the SD of the means are presented. GAPDH, glyceraldehyde 3-phosphate dehydrogenase. 
C

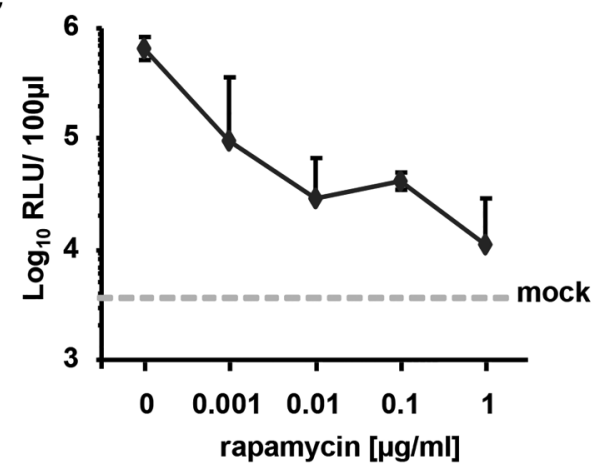

E

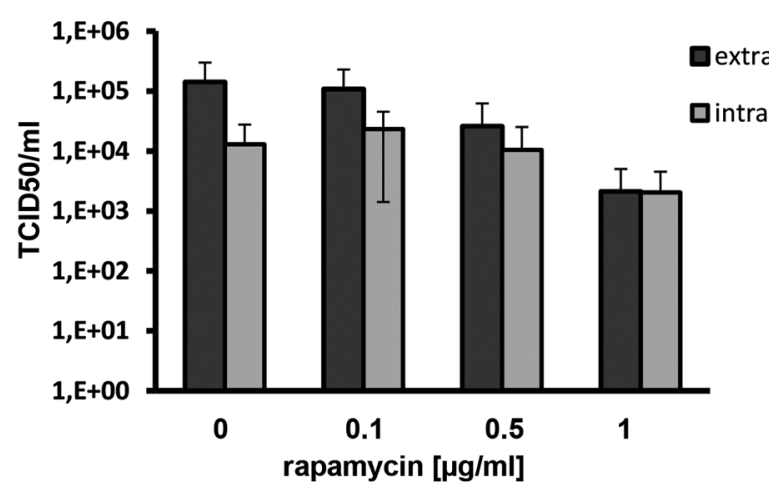

D
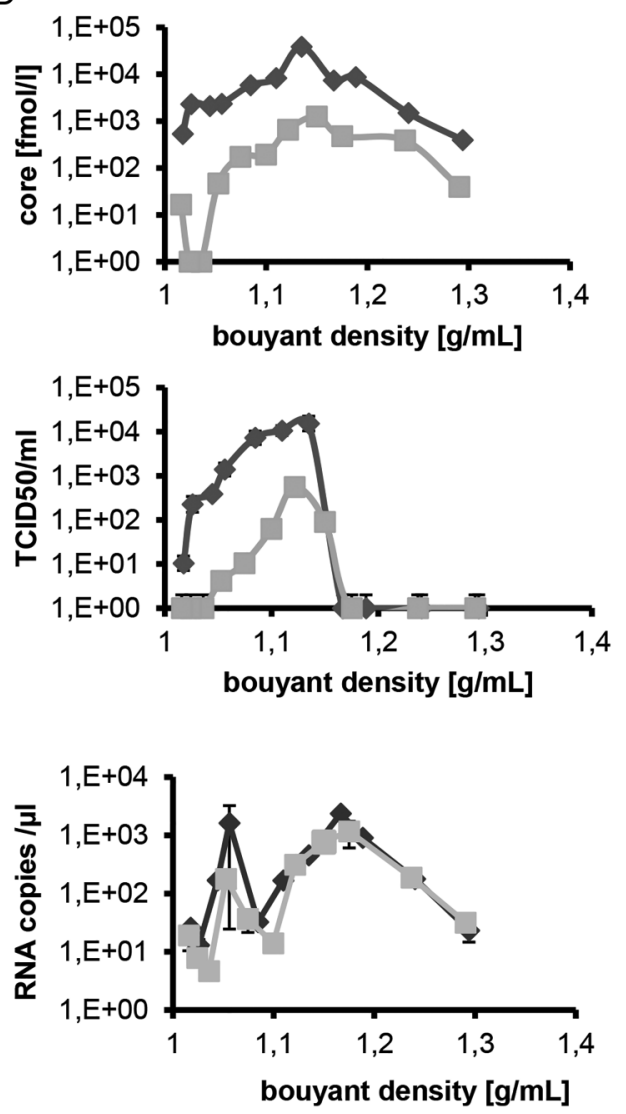

Figure 3 Continued

Huh-7.5/Fluc cells stably expressing firefly luciferase under control of a cytomegalovirus promoter. When these cells were exposed to rapamycin at concentrations of up to $1 \mu \mathrm{g} / \mathrm{mL}$ for $72 \mathrm{~h}$, the luciferase signal was unaffected (figure 2B).

In addition, cytotoxicity was investigated by propidium iodide (PI) staining (figure 2C) and MTT assay (figure 2D), confirming that the concentrations of rapamycin and everolimus that block HCV RNA replication were clearly not cytotoxic.

Taken together, mTOR inhibitors do not show any antiproliferative or cytotoxic effects in our assays at concentrations that were used for inhibition of HCV replication in this study.

\section{Rapamycin has no influence on new viral particle} production and the lipoprotein association of virus particles To further characterise how mTOR inhibitors affect HCV RNA replication, we assessed the amount of different HCV proteins in Jc1-transfected Huh-7.5 cells. Cells were treated with rapamycin for $48 \mathrm{~h}$, then viral protein expression was assessed by western blot (E2, NS2, NS5A) or ELISA (Core). The amount of intracellular and extracellular core protein, a structural component of HCV virions, was markedly reduced after treatment with rapamycin or everolimus (figure $3 \mathrm{~A}$ ), which was confirmed by western blot analysis (figure $3 \mathrm{~B}$ ). Moreover, also production of the viral proteins E2, NS2 and NS5A was reduced in a dosedependent manner after treatment with rapamycin for $48 \mathrm{~h}$ (figure 3B).

To confirm that the inhibitory effect of rapamycin is due to an alteration of the target cell rendering it HCV-resistant, we administered rapamycin $24 \mathrm{~h}$ prior to infection. Pretreatment of host cells with rapamycin prior to inoculation with the virus reduced HCV infection (figure 3C), indicating that rapamycin inhibits HCV by targeting the host cell and not the incoming viral particle.

It is well known that mTOR plays a key role in lipid homeostasis. To investigate whether mTOR inhibitors change lipid association of viral particles, we performed a gradient analysis of viral particles in the presence and absence of rapamycin. As shown in figure $3 \mathrm{D}$, we observed a reduced viral infectivity by treatment of rapamycin independent of the gradient density. The same effects can be noted when we determined viral core amounts by a commercial ELISA and viral RNA by qRT-PCR. These new data demonstrate that rapamycin is not affecting the lipoprotein association and/or biophysical integrity of virus particles.

In addition, we determined the effect of rapamycin on intracellular and extracellular virus particle infectivity and observed a dose-dependent reduction of both particles types. These results therefore indicate that in line with the reduced RNA replication also intracellular and extracellular virus infectivity is reduced and there is no additional inhibition of virus release (figure 3E).

\section{Inhibition of PI3K-PKB inhibits HCV RNA replication}

To exclude the possibility that the effect of rapamycin on HCV RNA replication represents an mTOR-independent off-target effect, we next wanted to investigate the effect of LY294002 on HCV. LY294002 is a well-characterised phosphoinositide-3kinase (PI3K) inhibitor acting upstream of the PI3K/mTOR signalling pathway. When Huh-7.5 cells were treated with non-toxic concentrations $(0-10 \mu \mathrm{M})$ of LY294002, a reduction of HCV RNA replication was detectable similar to that observed 

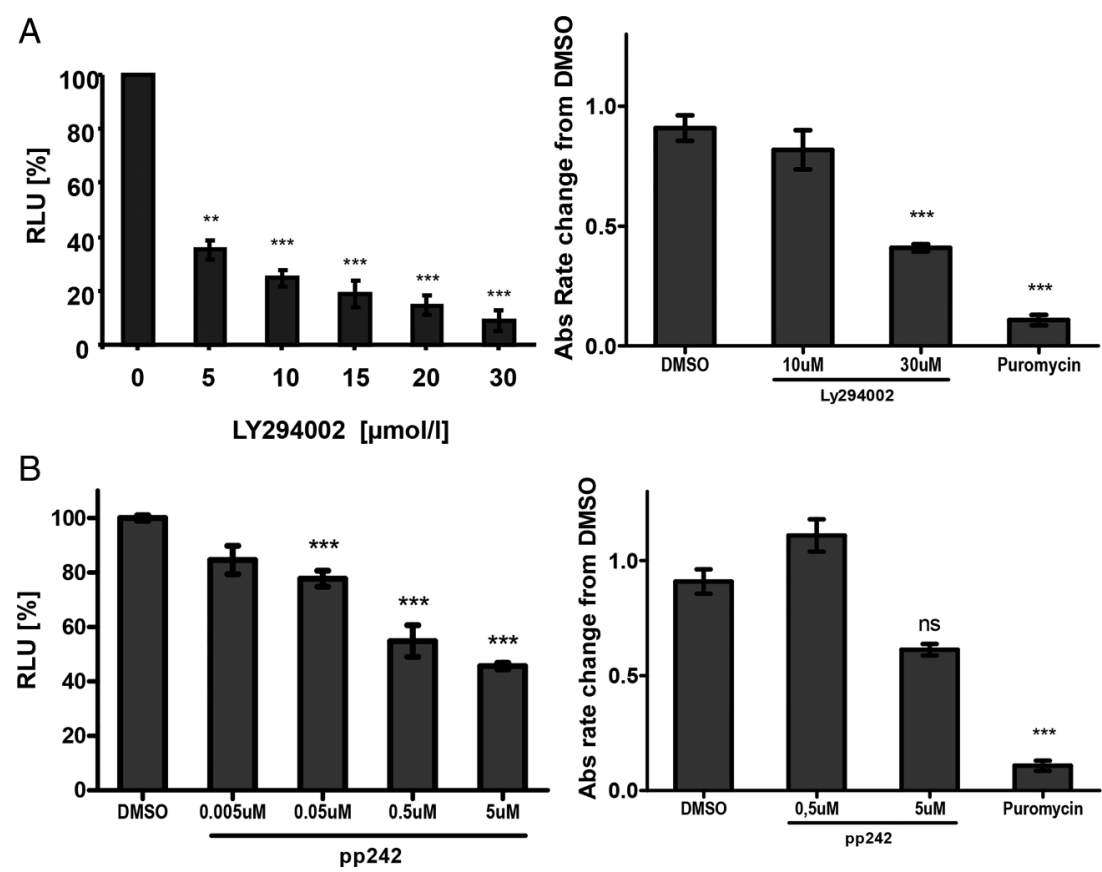

Figure 4 Inhibition of phosphoinositide-3-kinase (PI3K)-PKB inhibits HCV RNA replication. (A) Huh-7.5 cells were transfected with Luc-Jc1 reporter viruses. After $4 \mathrm{~h}$ incubation LY294002, an inhibitor of PI3K was added. Viral RNA replication was measured $48 \mathrm{~h}$ later by luciferase assay. Mean value and SEM of three independent experiments with two replicate measurements per drug concentration are shown (left panel). In addition, Huh-7.5 were incubated for $48 \mathrm{~h}$ with increasing concentrations of the drug. Cells were then incubated with $1.2 \mathrm{mM}$ MTT. Absorbance at $540 \mathrm{~nm}$ was then read on a plate reader. Mean values and SEM of three independent experiments with five replicates per drug concentration are shown. Puromycin was used as a positive control (right panel). ${ }^{*} p<0.05,{ }^{* *} p<0.01,{ }^{* *} p<0.001$ by one-way analysis of variance (ANOVA). (B) Huh-7.5 cells were transfected with Luc-Jc1 viruses. After $4 \mathrm{~h}$ incubation PP242, an inhibitor of mTORC1 and mTORC2, was added and amount of viral RNA replication was measured $48 \mathrm{~h}$ later by luciferase assay. Mean values and SEM of three independent experiments with five replicates per drug concentration are shown (left panel). In addition, Huh-7.5 were incubated for $48 \mathrm{~h}$ with increasing concentrations of the drug. Cells were then incubated with $1.2 \mathrm{mM}$ MTT. Absorbance at $540 \mathrm{~nm}$ was then read on a plate reader. Mean values and SEM of three independent experiments with three replicates per drug concentration are shown. Puromycin was used as a positive control (right panel). ${ }^{*} p<0.05,{ }^{* *} p<0.01,{ }^{* * *} p<0.001$ by one-way ANOVA. DMSO, dimethyl sulfoxide.

with rapamycin (figure 4A). This inhibitory effect was independent from cytotoxicity (figure 4A, right panel).

To investigate whether both mTOR complexes play a role in HCV replication cycle and simultaneous inhibition of both might have synergistic effects, the inhibitor PP242 was tested. PP242 is an ATP-competitive mTOR inhibitor affecting both mTORC1 and mTORC2 in contrast to rapamycin, which exclusively inhibits mTORC1. As shown in figure 4B, PP242 inhibits HCV similarly to rapamycin, but we could not detect any additive effect of inhibition of both mTOR complexes (figure 4B), indicating that mTORC1 is mainly responsible for $\mathrm{HCV}$ inhibition.

\section{Gene silencing of raptor by RNAi reduces HCV RNA replication}

The two mTOR complexes present in cells differ in that mTORC1 contains raptor while mTORC2 contains rictor. To evaluate the direct effects of raptor and rictor on HCV, Huh-7.5 cells were transduced with integrating lentiviral vectors expressing shRNA specifically targeting raptor, rictor or an irrelevant shRNA as a control (sh irrelevant). As shown in figure 5A, shRNA vectors targeting raptor and rictor achieved marked downregulation of the respective proteins. However, only raptor silencing resulted in a significant decrease of HCV RNA replication and production of new viral particles $(\mathrm{p}<0.001)$ while silencing of rictor had no significant effect on HCV. These data support that mTORC1, but not mTORC2, plays an important role in the HCV replication cycle.
To further elucidate mTORC1 involvement in the viral replication cycle, we examined the impact of mTOR-inhibitor treatment on expression of the mTORC1 proteins mTOR and raptor. Naive Huh-7.5 cells were treated with increasing concentrations of rapamycin or everolimus and incubated for 4, 24 or $48 \mathrm{~h}$. As shown in figure 5B, mTOR-inhibitor treatment leads to reduction of $\mathrm{mTOR}$ and raptor protein.

To show that raptor indeed plays a role during HCV replication, a cell line overexpressing raptor protein (pLJM1 Flag Raptor) was created. Overexpression was confirmed by western blot (figure 5C). Infection assays with raptor overexpressing cell lines revealed 1.5-fold higher HCV RNA replication levels compared with Huh-7.5 cells $(\mathrm{p}<0.01$, figure 5D).

These data show that mTORC1 plays an important role for HCV RNA replication. While downregulation of the mTORC1 protein raptor decreases RNA replication, overexpression of raptor enhances RNA replication. Since silencing of rictor has no effect on HCV, mTORC2 is likely not required for the HCV replication cycle.

Furthermore, these data indicate that rapamycin indeed targets mTORC1 and has no unforeseen direct off-target effect on a viral protein.

\section{Treatment with mTOR antagonists inhibits HCV RNA} replication in $\mathrm{PHH}$

Although Huh-7.5 cells sustain the complete HCV replication cycle, these carcinoma-derived cells functionally differ from $\mathrm{PHH}$. Therefore, PHH were inoculated with HCVcc in the 
A
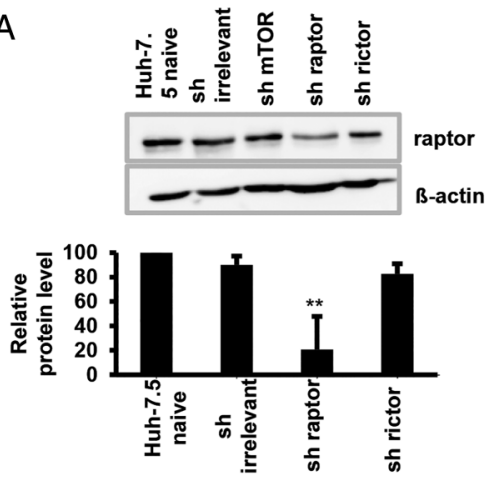
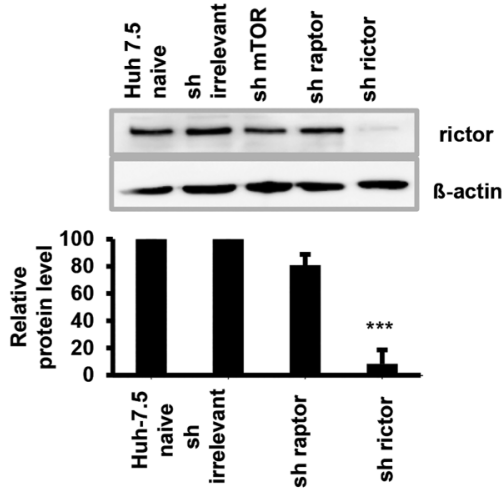

- replication

production of new particles
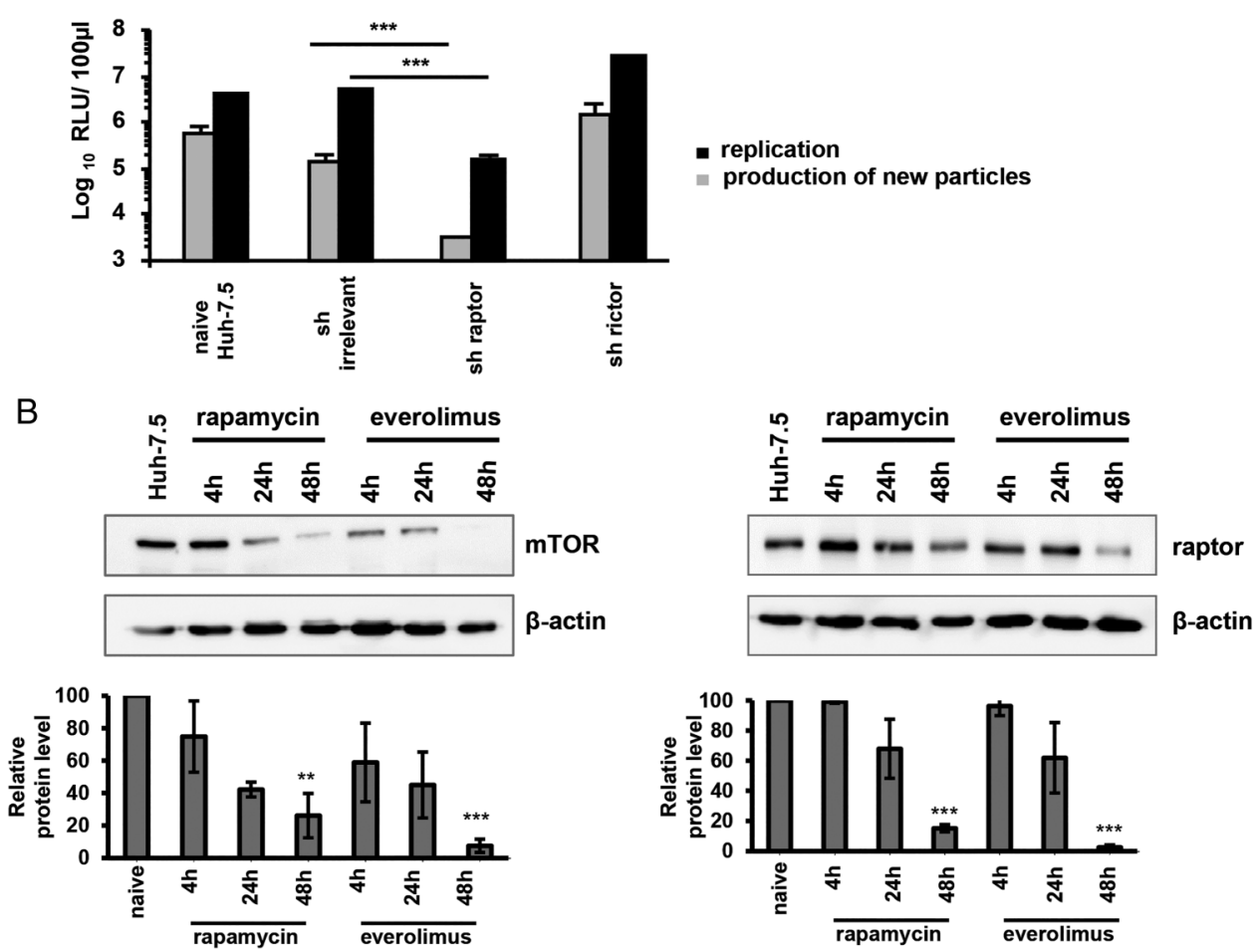

C
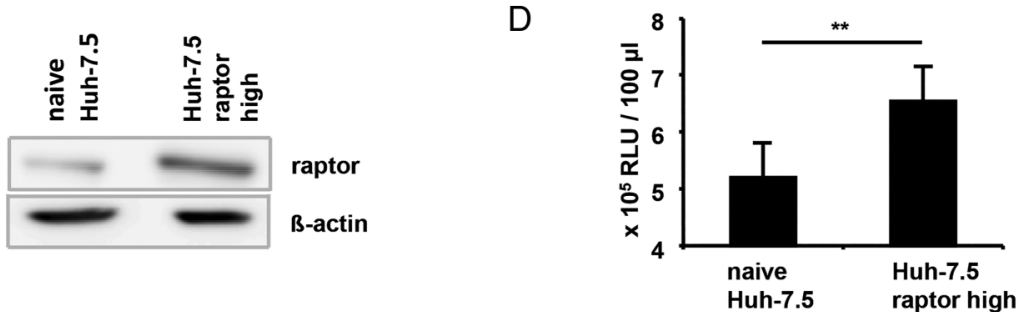

Figure 5 Gene silencing of raptor by RNAi reduces HCV RNA replication. (A). Huh-7.5 cells stably expressing shRNA's targeting raptor or rictor were characterised by western blot (upper panel) and transfected with Luc-Jc1 virus. Viral replication was measured $48 \mathrm{~h}$ later by luciferase activity (lower panel). Naive Huh-7.5 cells and a control cell line harbouring an irrelevant shRNA were used as positive controls. For production of new viral particles, culture fluid of the same cells was used to inoculate naive Huh7.5 cells. Infected cells were fixed 3 days later and luciferase activity was determined. A representative western blot and mean values of three independent experiments with SDs of the means is shown. ${ }^{*} p<0.05$, ${ }^{*} p<0.01$, ${ }^{* * *} p<0.001$ by one-way analysis of variance (ANOVA). (B) Naive Huh-7.5 cells were treated with $1 \mu \mathrm{g} / \mathrm{mL}$ rapamycin or $5 \mu \mathrm{g} / \mathrm{mL}$ everolimus. Expression of mammalian target of rapamycin (mTOR) and raptor protein was determined by western blot. A representative western blot and mean values of three independent experiments with SDs of the means is shown. ${ }^{*} p<0.05,{ }^{*}<0.01,{ }^{* *}<0.001$ by one-way ANOVA. (C) A raptor overexpressing Huh-7.5 cell line (Huh-7.5 raptor high, pLJM1 Flag Raptor) was created and raptor protein overexpression was confirmed by western blot. (D) Huh-7.5 raptor high and naive Huh-7.5 cells were transfected with Luc-Jc1 virus and HCV replication was measured by luciferase assay $48 \mathrm{~h}$ later. Mean values and SD of three independent experiments are shown. ${ }^{*} p<0.05,{ }^{* *} p<0.01,{ }^{* * *} p<0.001$ by one-way ANOVA.

presence or absence of rapamycin or everolimus and infectivity was determined through limiting dilution assay. Importantly, both drugs reduce HCV infectivity while rapamycin had overall a stronger inhibitory effect on $\mathrm{PHH}$ than everolimus (figure 6A). In addition, PI staining and MTT assay was performed on $\mathrm{PHH}$, confirming that the concentrations of 
A

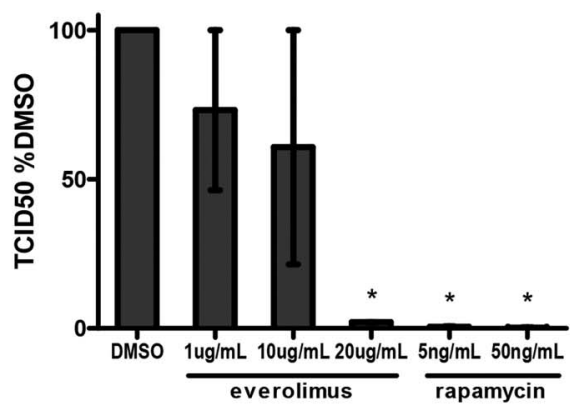

B

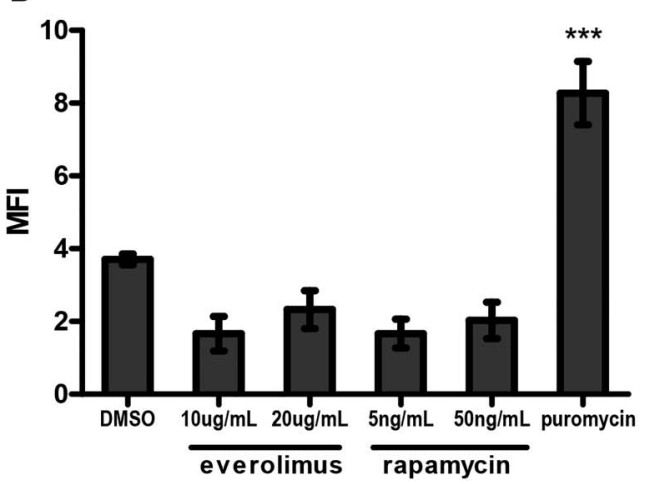

TCID50 48h incubation
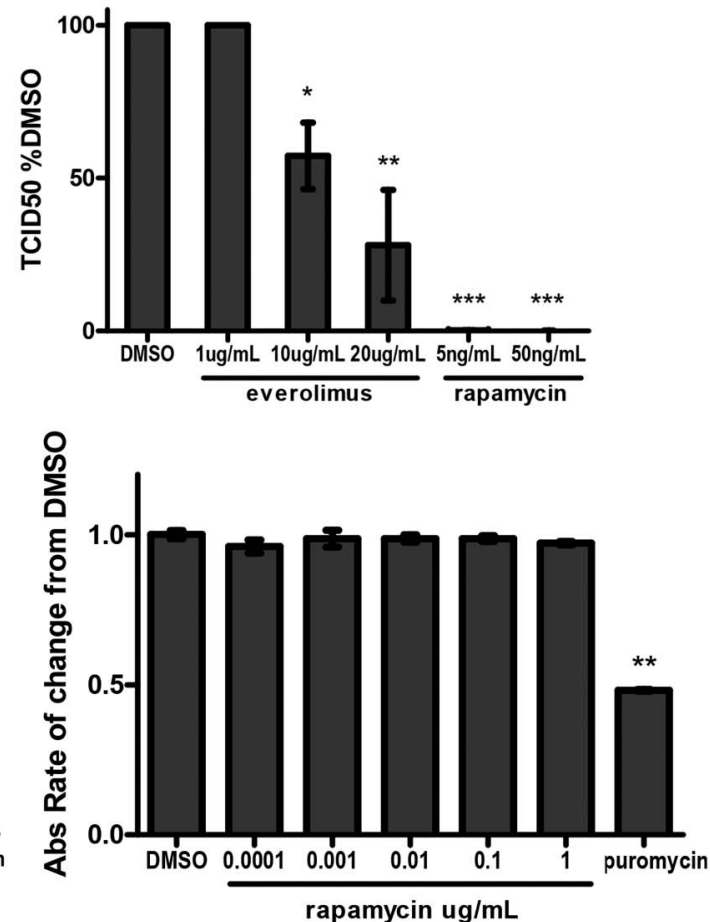

Figure 6 Mammalian target of rapamycin (mTOR) inhibition also decreases HCV RNA replication in primary human hepatocytes (PHH). (A) PHH were infected with Jc1 wildtype virus and treated with increasing concentrations of rapamycin or everolimus. Supernatants were collected after 24 and $48 \mathrm{~h}$ and infectivity was determined through limiting dilution assay. Mean values and SEM of two independent experiments are shown. ${ }^{*} p<0.05,{ }^{*} p<0.01,{ }^{* *} p<0.001$ by one-way analysis of variance (ANOVA). (B) PHH were incubated for $48 \mathrm{~h}$ in the presence of rapamycin or everolimus. Cells were then stained with propidium iodide. Dye Incorporation was measured by fluorescene-activated cell sorting. Mean fluorescence intensity (MFI) was determined using the geometric mean of the gated population. Mean values and SEM of three independent experiments are shown. Puromycin was used as a positive control (left panel). Cells were incubated with $1.2 \mathrm{mM}$ MTT. Absorbance at $540 \mathrm{~nm}$ was then read on a plate reader. Mean values and SEM of three independent experiments with five replicates per drug concentration are shown. Puromycin was used as a positive control (right panel). ${ }^{*} \mathrm{p}<0.05,{ }^{* *} \mathrm{p}<0.01,{ }^{* *} \mathrm{p}<0.001$ by one-way ANOVA. DMSO, dimethyl sulfoxide.

rapamycin and everolimus used for this experiments were not toxic for $\mathrm{PHH}$ (figure 6B).

These data indicate that mTOR antagonists do not only block $\mathrm{HCV}$ infection of hepatoma cell lines but also inhibit replication in $\mathrm{PHH}$.

\section{Knockdown of mTORC1 does not alter viral translation}

Inhibition of mTORC1 signalling is known to block translation of cellular RNAs. This led us to investigate whether mTORC1 is involved in viral RNA replication or, in addition, mainly viral RNA translation. Therefore, Huh-7.5 cells and Huh-7.5 cells

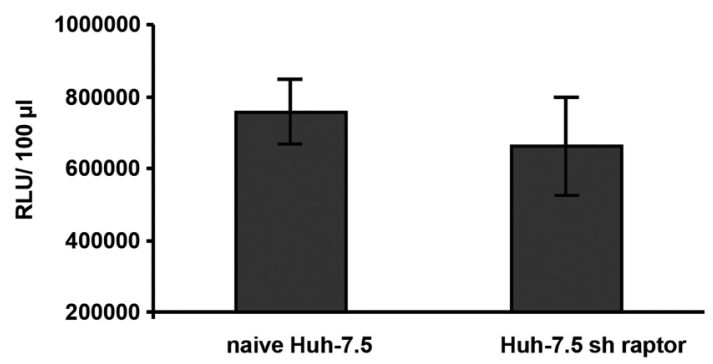

Figure 7 Knockdown of mTORC1 has no significant effect on viral translation. Huh-7.5 and Huh-7.5 sh raptor cells were transfected with a replication defective Luc-Jc1 $\triangle \mathrm{GDD}$ mutant and viral translation was measured $4 \mathrm{~h}$ later by luciferase activity. Mean values and SDs of four independent experiments are shown. expressing shRNA against raptor were transfected with the replication-defective Luc-Jc1 $\Delta$ GDD mutant. Luciferase signal was measured $4 \mathrm{~h}$ after electroporation. As shown in figure 7 , we could not observe any significant differences in translation efficacy in naive Huh-7.5 vs Huh-7.5 sh raptor cells

These data indicate that inhibition of mTORC1 rather effects RNA replication than translation of viral proteins.

mTOR inhibitors reduce HCV RNA levels in patients after liver and kidney transplantation

Between 2005 and 2014, 386 patients after kidney and liver transplantation at Hannover Medical School were switched to an immunosuppressive regimen including an mTOR inhibitor. Out of these, 67 patients were chronically infected with HCV genotype 1 . We retrieved available HCV RNA levels up to 4 weeks before and 4-12 weeks after addition of the mTOR inhibitor in this patient cohort from the patient files. We were thus able to follow-up the course of HCV RNA levels in 42 patients (figure 8A). In liver-transplanted as well as kidneytransplanted patients, HCV RNA levels were significantly reduced after introduction of the mTOR inhibitor, indicating that inhibition of mTOR also has an antiviral effect in vivo. Both mTOR inhibitors rapamycin and everolimus had a similar antiviral effect. Interestingly, decline of HCV RNA was more pronounced in patients after liver transplantation in comparison to kidney-transplanted individuals (figure $8 \mathrm{~B}$ ). 
A

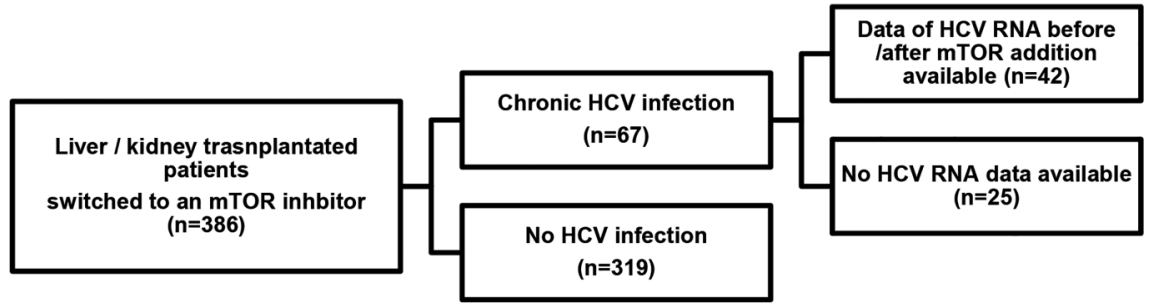

B

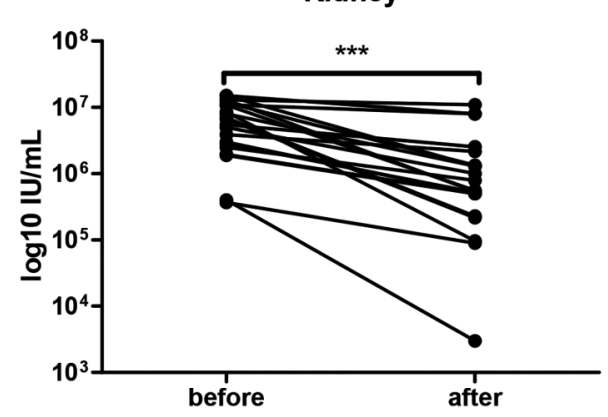

Kidney

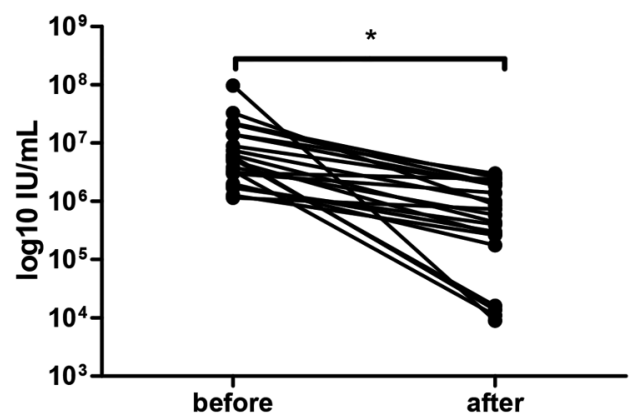

Figure 8 Mammalian target of rapamycin (mTOR) inhibition reduces HCV RNA levels in vivo. (A) Flow chart showing the selection process of participants enrolled in this analysis. (B) HCV RNA levels up to 4 weeks before and 4-12 weeks after changing the immunosuppressive regimen to an mTOR inhibitor were analysed by patient chart review in 42 patients after liver or kidney transplantation. There was no difference in type of mTOR inhibitor (everolimus or rapamycin). ${ }^{*} p<0.05,{ }^{* *} p<0.01,{ }^{* * *} p<0.001$ by two-tailed $t$ test.

\section{DISCUSSION}

In this study, we identified the mTOR inhibitors rapamycin and everolimus as potent inhibitors for HCV RNA replication. Inhibition of HCV by mTOR inhibitors (rapamycin and everolimus) was also detectable in differentiated Huh-7.5 cells and in $\mathrm{PHH}$, indicating that this effect is not related to their potential to inhibit cell proliferation. Treatment with rapamycin led to a reduction of HCV proteins E2, Core and non-structural proteins NS2 and NS5A, and thus the downregulation of several important viral proteins. The antiviral effect was not limited to a genotype 2a strain and was confirmed against an HCV genotype 3 chimeric virus. Furthermore, we determined that efficient HCV RNA replication is dependent on the presence of the mTORC1 signalling component raptor and that viral translation was not affected. In a single-centre cohort including $42 \mathrm{HCV}$ genotype 1 -infected patients after liver or kidney transplantation, we were able to verify that switch of the immunosuppressive regimen to an mTOR inhibitor is associated with a significant decline of HCV RNA levels. These findings have two important implications.

First, better outcomes for chronically HCV-infected patients after OLT are likely to depend on delivering antiviral and immunosuppressive agents simultaneously. In this study, inhibition of HCV replication was detected at concentrations that are achievable in the serum of transplant recipients. To this end, rapamycin and everolimus may be attractive agents as part of an immunosuppressive regimen for this special patient group. Rapamycin has been seen as an attractive immunosuppressant as it reduces the risk of significant hepatic fibrosis after OLT in HCV-positive patients ${ }^{31}$ and suppresses viral replication in vivo after solid organ transplantation, ${ }^{25}$ but the molecular reason for these observations had not been identified yet. Our data show for the first time that mTOR inhibitors directly inhibit important steps in the HCV replication cycle. Thus, mTOR inhibitors should be strongly considered as part of immunosuppressive regimens in HCV-positive patients as they may help to limit the extent of reinfection of the graft. Moreover, treatment of HCV recurrence after OLT is challenging due to drug interactions and contraindications for some antiviral agents. It will be interesting to see whether antiviral treatment will be more successful in patients receiving immunosuppressive regimens containing an mTOR inhibitor. Clinical studies will be necessary to clarify this point. Interestingly, HCV RNA reduction under mTOR-based immunosuppression was more pronounced in patients after liver transplantation than in kidney-transplanted patients. One possible reason for this might be that in our centre patients after kidney transplantation receive glucocorticosteroids while steroids were avoided in HCV-positive liver-transplanted patients.

We also have to keep in mind that mTOR is a key player in many cellular processes. One must consider that reduced liver damage after OLT upon rapamycin treatment might therefore be an indirect effect of direct inhibition of HCV replication. At this point, this hypothesis cannot be ruled out.

Second, our findings have implications for our understanding of HCV biology: mTOR inhibition leads to a reduction in HCV RNA replication and knockdown of raptor has a similar effect. In addition, overexpression of raptor enhances replication of HCV. Other steps of the viral lifecycle like entry, translation and production of novel viral particles were not affected. Thus, raptor as part of mTORC1 is a novel host factor that promotes HCV RNA replication in infected cells. Recently, McNulty et $a l^{32}$ could show that replication of Andes virus (ANDV), a member of the Hantavirus genus, also depends on mTORC1 signalling. However, mTOR primarily regulated ANDV protein expression and not ANDV RNA production. Therefore, ANDV and HCV likely depend on mTORC1 for different reasons. Moreover, our data suggest that mTORC1 is involved in HCV RNA replication rather than its translation. However, we were not able to show a direct co-localisation of mTOR and HCV viral proteins by immunofluorescence (data not shown) although both are localised in close proximity in the ER. This suggests that mTORC1 signalling promotes HCV replication indirectly. 
It has been shown by George $e t a l^{33}$ that HCV NS5A itself is able to activate mTORC1, which upregulates cap-dependent host protein translation and development of HCV-associated hepatocellular carcinoma. However, a direct link to viral replication and translation was not part of this study. In contrast, Huang et $a l^{34}$ published that HCV inhibits mTORC1 via ER stress and enhanced autophagy. In their experiments, HCV core protein level was not changed after activation of the mTORC1 pathway consistent with the hypothesis that inhibition of mTORC1 blocks RNA replication and not viral translation.

One possible explanation might be that mTORC1 is a key regulator in lipid homeostasis: it has been shown before that mTORC1 stimulates lipid synthesis via SREBP1 and influences lipolysis within lipid droplets. ${ }^{35}$ In addition, it is well known that lipid droplets play an essential role in multiple steps of the viral lifecycle of HCV such as infection, replication and assembly and release of new viral particles. ${ }^{36}{ }^{37}$ In line with this hypothesis, we also observed an enlargement of lipid droplets after treatment with rapamycin (data not shown) in HCV-infected cells similar to which was found by Andersson $e a^{38}$ after treatment with the cyclophilin inhibitor NIM811. However, we could not detect any differences in lipid composition of viral particles produced in cells treated with an mTOR inhibitor. Further detailed studies are necessary to evaluate the effects of rapamycin on SREBP1 and their influence on lipid droplet content.

Another possible explanation for the antiviral effect can be found downstream of mTOR signalling: the substrate p70 S6 kinase has been shown to phosphorylate PAK1 whose activity was reported to inhibit viral replication in hepatoma cells. In the same study, siRNA knockdown of p70 S6K abrogated PAK1 phosphorylation and enhanced viral replication, suggesting that this mechanism may be related to the antiviral effects of rapamycin and its analogues in the current study. ${ }^{39}$

In contrast to our data and the above-mentioned work, Beretta et al reported a promoting effect arising from Pi3K inhibition on HCV replication. ${ }^{40}$ They showed that the $\mathrm{N}$-Ras-Pi3K-Akt-mTOR is important in regulating viral replication rates in retinoic acid inducible gene 1 (RIG-I) competent cell lines by modulating the phosphorylation state of the viral protein NS5A. Curiously, we also could observe a slight increase of HCV RNA replication at subtherapeutical concentrations of both mTOR inhibitors, which is in line with Beretta et al who used Pi3K inhibitors although at much lower concentrations. We cannot rule out that differences between HCV genotypes may play a role in the observed effects as Beretta $e t$ al reported on a genotype $1 \mathrm{~b}$ strain. Furthermore, a major difference in comparison to our work is that Beretta et al used the RIG-I competent Huh 7 cell line while we were using Huh-7.5 cells, which are known to have a mutated RIG-I. Nonetheless, this observation raises an interesting question about mTOR modulation by viral activity. Not only response to Pi3K inhibition from the virus appears to be different in Huh7 and Huh-7.5 cell lines but also viral replication exhibits an interesting dichotomy of responses when the cells are stimulated with substances that alter mTOR signalling. ${ }^{40}$

In summary, we have discovered that mTORC1 is required for efficient HCV RNA replication and that mTOR inhibitors may be useful as part of immunosuppressive regimens for HCV-positive individuals after OLT or transplantation of other solid organs. We can thus explain the clinical observation made in several studies that rapamycin-containing regimens are associated with better patient outcome in HCV-positive individuals after solid organ transplantation. Moreover, we provide data suggesting that raptor as part of mTORC1 is a novel host factor for HCV RNA replication.

\section{Author affiliations}

${ }^{1}$ Department of Gastroenterology, Hepatology and Endocrinology, Medizinische Hochschule Hannover, Hannover, Germany

${ }^{2}$ German Center for Infection Research (DZIF), Hannover, Germany

${ }^{3}$ Institute for Molecular Biology, Medizinische Hochschule Hannover, Hannover, Germany

${ }^{4}$ Division of Experimental Virology, TWINCORE, Centre for Experimental and Clinical Infection Research; a joint venture between the Medical School Hannover (MHH) and the Helmholtz Centre for Infection Research (HZI), Hannover, Germany

${ }^{5}$ Cell Growth and Development Biozentrum, Universität Basel, Basel, Switzerland

${ }^{6}$ Center for Vaccinology, Ghent University, Ghent University Hospital, Ghent, Belgium ${ }^{7}$ Department of General, Visceral and Transplantation Surgery, Medizinische Hochschule Hannover, Hannover, Germany

${ }^{8}$ Integrated Research and Treatment Centre-Transplantation (IFB-TX), Hannover, Germany

Acknowledgements We are grateful to Takaji Wakita, for JFH1, to Charles Rice for Huh-7.5 cells and E9E10 and 6H6 monoclonal antibody, to Darius Moradpour for C7-50 antibody and to Arvind Patel for AP33 antibody. We thank David Sabatini for shRNA constructs targeting raptor, rictor, mTOR and scrambled RNA and pLJM1 Flag raptor. We thank Michael Engelmann and Corinna Löbbert for excellent technical assistance and Norman Woller for expert advice.

Contributors SS and RC contributed equally. SS: acquisition of data, analysis and interpretation of data. RC and LS and SP and TvH: acquisition of data, analysis and interpretation of data. SW: analysis and interpretation of data. A and PM: acquisition of data. EDK and ES: material support, analysis and interpretation of data. FWRV and MPM: material support. SC: study concept and design, acquisition of data, analysis and interpretation of data, drafting of the manuscript, obtained funding

Funding This work was supported by Deutsche Forschungsgemeinschaft through collaborative research centre 738, by the Germany Center for Infection Research (DZIF) and the Integrated Research and Treatment Centre-Transplantation (IFB-Tx). RC is a scholar of the Hannover Biomedical Research School.

Competing interests None declared.

Ethics approval Ethics Committee of Hannover Medical School.

Provenance and peer review Not commissioned; externally peer reviewed.

Open Access This is an Open Access article distributed in accordance with the Creative Commons Attribution Non Commercial (CC BY-NC 4.0) license, which permits others to distribute, remix, adapt, build upon this work non-commercially, and license their derivative works on different terms, provided the original work is properly cited and the use is non-commercial. See: http://creativecommons.org/ licenses/by-nc/4.0/

\section{REFERENCES}

1 Ciesek S, Wedemeyer $\mathrm{H}$. Immunosuppression, liver injury and post-transplant HCV recurrence. J Viral Hepat 2012;19:1-8.

2 Ciesek S, Manns MP. Hepatitis in 2010: the dawn of a new era in HCV therapy. Nat Rev Gastroenterol Hepatol 2011;8:69-71.

3 Manns MP, von Hahn T. Novel therapies for hepatitis C-one pill fits all? Nat Rev Drug Discov 2013:12:595-610.

4 Delemos AS, Chung RT. Hepatitis C treatment: an incipient therapeutic revolution. Trends Mol Med 2014;20:315-21.

5 Gurusamy KS, Tsochatzis E, Toon CD, et al. Antiviral prophylaxis for the prevention of chronic hepatitis $C$ virus in patients undergoing liver transplantation. Cochrane Database Syst Rev 2013;12:CD006573.

6 Coilly A, Roche B, Samuel D. Current management and perspectives for HCV recurrence after liver transplantation. Liver Int 2013;33(Suppl 1):56-62.

7 Berenguer $M$, Prieto $M$, Palau $A$, et al. Severe recurrent hepatitis $C$ after liver retransplantation for hepatitis C virus-related graft cirrhosis. Liver Transp/ 2003;9:228-35.

8 Sainz B, Chisari FV. Production of infectious hepatitis C virus by well-differentiated, growth-arrested human hepatoma-derived cells. J Virol 2006;80:10253-7.

9 Terrault N. Liver transplantation in the setting of chronic HCV. Best Pract Res Clin Gastroenterol 2012;26:531-48.

10 Vinaixa $C$, Rubin A, Aguilera $V_{\text {, et }}$ al. Recurrence of hepatitis $C$ after liver transplantation. Ann Gastroenterol 2013;26:304-13.

11 Ciesek S, Steinmann E, Iken M, et al. Glucocorticosteroids increase cell entry by hepatitis C virus. Gastroenterology 2010;138:1875-84.

12 Gedaly R, Clifford TM, McHugh PP, et al. Prevalent immunosuppressive strategies in liver transplantation for hepatitis $C$ : results of a multi-center international survey. Transpl Int 2008;21:867-72. 
13 Brown EJ, Albers MW, Shin TB, et al. A mammalian protein targeted by G1-arresting rapamycin-receptor complex. Nature 1994;369:756-8.

14 Betz C, Hall MN. Where is mTOR and what is it doing there? J Cell Biol 2013;203:563-74.

15 Sengupta S, Peterson TR, Sabatini DM. Regulation of the mTOR complex 1 pathway by nutrients, growth factors, and stress. Mol Cell 2010;40:310-22.

16 Vazquez-Martin A, Cufi S, Oliveras-Ferraros C, et al. Raptor, a positive regulatory subunit of mTOR complex 1 , is a novel phosphoprotein of the rDNA transcription machinery in nucleoli and chromosomal nucleolus organizer regions (NORs). Cell Cycle 2011:10:3140-52.

17 Ekim B, Magnuson B, Acosta-Jaquez HA, et al. mTOR kinase domain phosphorylation promotes mTORC1 signaling, cell growth, and cell cycle progression. Mol Cell Biol 2011;31:2787-801.

18 Yang $H$, Rudge DG, Koos JD, et al. mTOR kinase structure, mechanism and regulation. Nature 2013;497:217-23.

19 Jacinto $E$, Loewith $R$, Schmidt $A$, et al. Mammalian TOR complex 2 controls the actin cytoskeleton and is rapamycin insensitive. Nat Cell Biol 2004;6:1122-8.

20 Sarbassov DD, Ali SM, Sengupta $S$, et al. Prolonged rapamycin treatment inhibits mTORC2 assembly and Akt/PKB. Mol Cell 2006;22:159-68.

21 Klintmalm GB, Nashan B. The role of mTOR inhibitors in liver transplantation: reviewing the evidence. J Transplant 2014;2014:845438.

22 Nashan B. Induction therapy and mTOR inhibition: minimizing calcineurin inhibitor exposure in de novo renal transplant patients. Clin Transplant 2013;27(Suppl 25):16-29.

23 McKenna GJ, Trotter JF, Klintmalm E, et al. Limiting hepatitis C virus progression in liver transplant recipients using sirolimus-based immunosuppression. $\mathrm{Am} \mathrm{J}$ Transplant 2011;11:2379-87.

24 Asthana S, Toso C, Meeberg G, et al. The impact of sirolimus on hepatitis C recurrence after liver transplantation. Can J Gastroenterol 2011;25:28-34.

25 Soliman A, Fathy A, Khashab S, et al. Sirolimus conversion may suppress viral replication in hepatitis $C$ virus-positive renal transplant candidates. Exp Clin Transplant 2013;11:408-11.

26 Peng $L$, Liang $D$, Tong $W$, et al. Hepatitis $C$ virus NS5A activates the mammalian target of rapamycin (mTOR) pathway, contributing to cell survival by disrupting the interaction between FK506-binding protein 38 (FKBP38) and mTOR. J Biol Chem 2010;285:20870-81.
27 Bose SK, Meyer K, Di Bisceglie AM, et al. Hepatitis C virus induces epithelialmesenchymal transition in primary human hepatocytes. J Virol 2012;86:13621-8.

28 Bose SK, Shrivastava S, Meyer K, et al. Hepatitis C virus activates the mTOR/S6K1 signaling pathway in inhibiting IRS-1 function for insulin resistance. J Virol 2012;86:6315-22.

29 Burgel $B$, Friesland $M$, Koch $A$, et al. Hepatitis $C$ virus enters human peripheral neuroblastoma cells - evidence for extra-hepatic cells sustaining hepatitis $C$ virus penetration. J Viral Hepat 2011;18:562-70.

30 Anggakusuma, Frentzen A, Gurlevik E, et al. Control of hepatitis C virus replication in mouse liver-derived cells by MAVS-dependent production of type I and type III interferons. J Virol 2015;89:3833-45.

31 Kelly MA, Kaplan M, Nydam T, et al. Sirolimus reduces the risk of significant hepatic fibrosis after liver transplantation for hepatitis C virus: a single-center experience. Transplant Proc 2013;45:3325-8.

32 McNulty S, Flint M, Nichol ST, et al. Host mTORC1 signaling regulates andes virus replication. J Virol 2013;87:912-22.

33 George A, Panda S, Kudmulwar D, et al. Hepatitis C virus NS5A binds to the mRNA cap-binding eukaryotic translation initiation $4 \mathrm{~F}$ (elF4F) complex and up-regulates host translation initiation machinery through elF4E-binding protein 1 inactivation. J Biol Chem 2012;287:5042-58.

34 Huang H, Kang R, Wang J, et al. Hepatitis C virus inhibits AKT-tuberous sclerosis complex (TSC), the mechanistic target of rapamycin (MTOR) pathway, through endoplasmic reticulum stress to induce autophagy. Autophagy 2013;9:175-95.

35 Ricoult SJ, Manning BD. The multifaceted role of mTORC1 in the control of lipid metabolism. EMBO Rep 2013;14:242-51.

36 McLauchlan J. Lipid droplets and hepatitis C virus infection. Biochim Biophys Acta 2009;1791:552-9.

37 Ogawa K, Hishiki T, Shimizu Y, et al. Hepatitis C virus utilizes lipid droplet for production of infectious virus. Proc Jpn Acad Ser B Phys Biol Sci 2009;85:217-28.

38 Anderson $\mathrm{L}$, Lin $\mathrm{K}$, Compton $\mathrm{T}$, et al. Inhibition of cyclophilins alters lipid trafficking and blocks hepatitis C virus secretion. Virol J 2011;8:329.

39 Ishida H, Li K, Yi M, et al. p21-activated kinase 1 is activated through the mammalian target of rapamycin/p70 S6 kinase pathway and regulates the replication of hepatitis C virus in human hepatoma cells. J Biol Chem 2007;282:11836-48.

40 Mannova P, Beretta L. Activation of the N-Ras-PI3K-Akt-mTOR pathway by hepatitis C virus: control of cell survival and viral replication. J Virol 2005;79:8742-9. 